\title{
Epidemiología molecular de Streptococcus pneumoniae
}

\author{
MOLECULAR EPIDEMIOLOGY OF Streptococcus pneumoniae
}

\author{
MARÍA HORTAL ${ }^{1,3,4}$ y TERESA CAMOU. ${ }^{2}$
}

Genetic events and selective pressure lead microbes to change and for new diseases to emerge and new epidemics to occur.

A.S. Fauci.

\section{INTRODUCCIÓN}

La epidemiología molecular permite reconocer características genéticas de las bacterias no reveladas por las técnicas de laboratorio convencionales. En las últimas décadas, las ciencias básicas lograron un importante desarrollo tecnológico que ha posibilitado esa epidemiología molecular. Esta ha proporcionado una nueva visión, no adquirida por las técnicas fenotípicas, sobre las características biológicas de Streptococcus pneumoniae y su comportamiento dinámico. S. pneumoniae es naturalmente competente para la transformación genética. Este mecanismo le permite incorporar ADN externo que es asimilado al cromosoma bacteriano a través de eventos de recombinación, constituyéndose en el "motor" principal de su proceso evolutivo. Su presencia frecuente en la flora orofaríngea de portadores (fundamentalmente de niños), en la que participa junto a otras numerosas especies bacterianas, le proporciona un nicho ecológico adecuado para este intercambio genético. Así el neumococo, a través de genes o segmentos de genes derivados de la misma especie o de otros estreptococos, o por incorporación de elementos móviles (transposones), o, en menor medida por mutaciones, puede adquirir propiedades que le permitan evadir presiones selectivas específicas, tales como una respuesta inmunológica del hospedero o un tratamiento con antimicrobianos.

\section{Susceptibilidad de Streptococcus pneumoniae a penicilina}

Streptococcus pneumoniae resistentes a penicilina. Uno de los fenómenos más exhaustivamente estudiados en un nivel molecular es la resistencia a penicilina. Las cepas resistentes poseen alteraciones en determinadas proteínas de unión a penicilina (PBP) que disminuyen su afinidad natural por el fármaco. En los genes $p b p 1 A, p b p 2 B$ y $p b p 2 X$ de las cepas resistentes se observa una estructura en "mosaico", en la que se alternan segmentos con un alto grado de homología con los neumococos sensibles, con otros similares a los observados en cepas de Streptococcus mitis y Streptococcus oralis.

Los resultados de los sistemas de vigilancia de las neumococcias en el concierto internacional indicaban que la resistencia a penicilina había surgido simultáneamente en regiones geográficas distantes. Los estudios de epidemiología molecular evidenciaron que efectivamente, esa resistencia en $S$. pneumoniae era el resultado de eventos independientes entre sí, que involucraban cepas de diversos serotipos y linajes genéticos.

Sin embargo, en ese escenario de alta diversidad, se destacaban claramente algunos clones que alcanzaron rápidamente una difusión intercontinental, ignorándose por el momento las razones de esa prevalencia. Por ejemplo, un clon serotipo $23 \mathrm{~F}$ altamente resistente a los $\beta$-lactámicos (CIM $>2 \mu \mathrm{g} / \mathrm{ml}$ ), tam-

Programa OPS/SIREVA en Uruguay: ${ }^{1}$ Departamento Materno - Infantil. ${ }^{2}$ Departamento Laboratorios de Salud, Ministerio de Salud Pública. ${ }^{3}$ Ministerio de Salud Pública. ${ }^{4}$ Programa para Desarrollo de las Ciencias Básicas (PEDECIBA) Universidad de la República. Teresa Camou PH. D., efectuó una tesis de doctorado en PEDECIBA sobre "Epidemiología molecular de Streptococcus pneumoniae clínicamente relevantes". 
bién resistente a cotrimoxazol, cloranfenicol y tetraciclina, fue identificado en España en la década de los 80, diseminándose a países de los cinco continentes. La introducción en Islandia de otro clon 6B, del mismo origen, provocó un aumento dramático de la resistencia a penicilina en ese país. Actualmente, un grupo internacional de expertos, Pneumococcal Molecular Epidemiology Network (www.wits.ac.za/ pmen) ha propuesto una nomenclatura general para identificar los clones.

En Latinoamérica, la existencia desde 1994 de una red de vigilancia de las afecciones neumocóccicas en niños, organizada por SIREVA-OPS, había proporcionado valiosa información sobre la distribución de serotipos y la resistencia a penicilina. En el marco de ese proyecto, se organizó en 1997 un taller en la Universidad de Rockefeller en el que representantes de Argentina, Brasil, Chile, Colombia, México y Uruguay caracterizaron genéticamente una colección de cepas de S. pneumoniae resistentes a penicilina. Los porcentajes de aislamientos con sensibilidad disminuida a penicilina eran diferentes entre los países (desde 15\% en Colombia hasta $48 \%$ en México) observándose también diferencias en los genotipos identificados en cada país. Sin embargo, una conclusión sorprendente fue que $80 \%$ de las cepas con CIM $=1 \mu \mathrm{g} / \mathrm{ml}$ pertenecían a 2 clones internacionales:

- el clon serotipo $23 \mathrm{~F}$ de origen español, aislado en todos los países excepto Brasil. Este predominaba claramente en México (70\%) y en menor medida en Colombia (40\%), pero resultó poco frecuente en Chile, Uruguay y Argentina; y

- un clon France ${ }^{9 \mathrm{v}}-3$, que expresaba alternativamente los serotipos 14 (91\%), 9V (7\%) y en un caso el 19F. Este clon 14 predominaba ampliamente en Uruguay $(93 \%)$ y Argentina (85\%), siendo medianamente frecuente en Brasil y Colombia y poco frecuente en Chile y México.

En contraste con la prevalencia de estos clones, los aislamientos con CIM para penicilina de 0,1 a $0,5 \mu \mathrm{g} / \mathrm{ml}$ mostraban una gran diversidad genética, y ninguna similitud con otros clones internacionales. Se identificaron algunos agrupamientos clonales de origen local ( 4 en Brasil, 2 en Colombia y 1 en Chile) que juntos representaban 56\% de estos aislamientos.

En conclusión, el aumento de la resistencia a penicilina en S. pneumoniae invasores de Latinoamérica es el resultado de dos fenómenos epidemiológicos concomitantes:

- la importación de clones internacionales que poseerían atributos especiales de virulencia y "epidemicidad" y
- múltiples eventos de transferencia de resistencia a cepas sensibles, que ocurren de manera independiente y localizada.

Streptococcus pneumoniae sensibles a penicilina Estudios preliminares sugerían que la clonalidad no era un fenómeno exclusivo de las cepas resistentes a penicilina, sino que ésta podría ser seleccionada por la capacidad de supervivencia y/o virulencia de determinadas cepas de $S$. pneumoniae. Con el fin de comprobar esta hipótesis, Enright et al analizaron 274 aislamientos invasores de ocho países utilizando un nuevo método, la tipificación por secuencias multilocus (MLST), lo que permitió iniciar una base internacional de datos sobre la epidemiología molecular de $S$. pneumoniae (http://mlst.zoo.ox.ac.uk). Si bien esa colección mostró una gran diversidad genética con 143 genotipos, 12 de ellos contenían al menos 5 aislamientos de diferentes países. Estos clones internacionales eran (salvo uno) sensibles a penicilina. Algunas cepas de Uruguay (único país latinoamericano que participó del estudio) de los serotipos 7F y $12 \mathrm{~F}$ correspondieron a dos de los clones prevalentes.

Para caracterizar genéticamente a las cepas invasoras más frecuentes, se siguen realizando intensos esfuerzos para identificar clones con atributos especiales para causar infecciones severas.

Aparentemente, algunos serotipos son expresados en aislamientos de múltiples linajes diferentes (ej. serotipo 14), probablemente como resultado de frecuentes reemplazos de serotipos en cepas con historias evolutivas diferentes. En otros casos, neumococos de un mismo serotipo comparten un origen clonal común (ej. serotipos 7F, 12F, 37). Algunas de las propuestas para explicar el mantenimiento de la identidad genética, son su escasa frecuencia en portadores sanos, lo que restringe las oportunidades de intercambio genético horizontal (ej. serotipo 12F), o la mayor producción de material capsular, que actuaría como barrera de ese intercambio (ej.serotipo 37).

En Colombia, aislamientos del serotipo 5 susceptibles a penicilina y resistentes a cloranfenicol, fueron confirmados como pertenecientes a un clon, propuesto a la red internacional como Colombia 5 -19. El análisis ulterior de aislamientos invasores del serotipo 5 de Uruguay, Argentina, Brasil y México indicó que todas estas cepas están genéticamente relacionadas, aun aquellas sensibles al cloranfenicol, prevalentes en Argentina y Uruguay. Estos resultados demostrarían, en este serotipo, una identidad clonal común, mantenida a través del tiempo y con expansión geo- 
gráfica continental. También en este caso esta estabilidad genética podría explicarse por su escasa participación en la flora orofaríngea.

\section{Transferencia de genes de cápsula}

Ya en los años 70/80, se estudió la distribución mundial de serotipos asociados con afecciones neumocóccicas invasoras para definir las fórmulas de las vacunas polisacarídicas 14 y 23 -valentes. En la actualidad, basados en la frecuencia de serotipos involucrados en enfermedades severas del niño bajo 5 años de edad, se propusieron 7, 9 y hasta 11 serotipos para ser incluídos en las diferentes fórmulas de vacunas conjugadas.

Una premisa a tener en cuenta en la aplicación de esas vacunas es la comprobación de que $S$. pneumoniae idénticos con respecto a todos los marcadores genéticos empleados, inclusive los determinantes de resistencia, pueden expresar diferentes serotipos capsulares. Se demostró que esos cambios de serotipo eran el resultado de una transferencia genética horizontal entre neumococos, que involucraba los genes de biosíntesis de cápsula, permitiendo, probablemente, evadir la respuesta inmunológica del hospedero. Es de destacar que en la mayor parte de los casos documentados, los serotipos adquiridos eran, por ejemplo, 19F y 14 , los cuales son pobremente inmunogénicos en niños.

$\mathrm{El}$ análisis de la secuencia de ADN de los genes capsulares de 8 aislamientos del serotipo 19F, variantes del clon multiresistente Spain ${ }^{23 F}-1$, que usualmente expresa el serotipo 23F, sugiere que éstos emergieron en al menos 4 ocasiones diferentes.

Otro ejemplo es el clon France ${ }^{9 \mathrm{v}}-3$, descrito en Francia y España en la década del 80, originalmente del serotipo 9V, del que luego se identificaron variantes serotipo 14, tanto en esos países europeos, como en los seis países latinoamericanos. Estudiando esas variantes del serotipo 14 se logró documentar dos eventos independientes de reemplazo de serotipo: mientras que los aislamientos de Uruguay, España y Dinamarca eran idénticos entre sí, las variantes serotipo 14 de Polonia presentaban algunas diferencias en la secuencia de nucleótidos. En ambos casos, la recombinación no sólo había involucrado a los genes capsulares, sino que incluía al gen pbplA, como consecuencia de su proximidad en el cromosoma.

El fenómeno de cambio de serotipo ha sido documentado fundamentalmente en cepas resistentes a penicilina, pero seguramente involucra a la especie en su totalidad. Se ha especulado que las presiones selectivas masivas, como las ejercidas por vacunas, podrían potenciar este mecanismo, que aparentemente ya ocurre con relativa frecuencia en la naturaleza. Una vacuna con un número limitado de serotipos podría ser sumamente efectiva durante un tiempo, pero paulatinamente los individuos vacunados podrían ser infectados por cepas que hubieran adquirido, por intercambio de material genético, otros serotipos no incluidos en la vacuna, manteniendo su potencial de virulencia intacto.

Un aspecto clave radica en la eficacia de las vacunas en prevenir la colonización orofaríngea por serotipos incluidos en la fórmula y por lo tanto evitar su circulación. Si es posible lograr ese objetivo, las posibilidades de intercambio genético entre cepas virulentas de esos serotipos y cepas menos virulentas de otros serotipos se verían notablemente disminuidas.

También se ha observado en estudios de campo que los individuos vacunados experimentan una sustitución en su flora orofaríngea por serotipos no incluídos en la fórmula. Se considera que estos serotipos, dada su baja o nula participación en procesos invasores, no estarían dotados de ciertos factores de virulencia. Sin embargo, como ya se ha destacado, S. pneumoniae tiene una gran capacidad para incorporar material genético y se ha demostrado que este intercambio no se limita a los genes capsulares y a los determinantes de resistencia ya mencionados, sino que incluye otras estructuras de superficie involucradas en la virulencia, las que podrían ser adquiridas por neumococos "no virulentos".

En conclusión puede señalarse que:

- La complejidad de la dinámica evolutiva de $S$. pneumoniae hace imprescindible el empleo de técnicas de epidemiología molecular para lograr sistemas de vigilancia más completos tanto a nivel nacional como internacional, y así reconocer las características genotípicas de las cepas prevalentes en cada área geográfica.

- En las etapas post-aplicación masiva de vacunas conjugadas, el monitoreo en un nivel molecular de los aislamientos, tanto invasores como de colonización, darán un panorama cabal de la interacción entre las presiones selectivas y los eventuales intercambios de cápsula y/o de determinantes de patogenicidad. 


\section{BIBLIOGRAFÍA}

1.- COFFEY T J, DOWSON C G, DANIELS M, SPRATT B G. Genetics and molecular biology of $\beta$-lactam-resistant pneumococci. Microb Drug Resist 1995; 1: 29-34.

2.- COFFEY T J, DANIELS M, ENRIGHT M C, SPRATT B G. Serotype 14 variants of the Spanish penicillinresistant serotype $9 \mathrm{~V}$ clone of $S$. pneumoniae arose by large recombinational replacements of the cpsA-pbpla region. Microbiol 1999; 145: 2023-31.

3.- ENRIGHT MC, SPRATT B G. A multilocus sequence typing scheme for $S$. pneumoniae: identification of clones associated with serious invasive disease. Microbiol 1998; 144: 3049-60.

4.- MUSSER J M. Molecular population genetic analysis of emerged bacterial pathogens: selected insights. Emerg Infect Dis 1996; 2: 1-17.

5.- TOMASZ A, CORSO A, and the members of the PAHO/ Rockefeller University Workshop: SEVERINA E P, ECHANIZ-AVILES G, DE CUNTO BRANDILEONE M C, CAMOU T, CASTAÑEDA E, FIGUEROA O, ROSSI A DI FABIO J L. Molecular epidemiologic characterization of penicillin-resistant Streptococcus pneumoniae invasive pediatric isolates recovered in six Latin American countries: an overview. Microb Drug Resist 1998; 4: 195-207.

Correspondencia a:

María Hortal

Mail: mhortal@st.com.uy

\title{
Proyecciones de las vacunas anti neumocóccicas conjugadas en Latinoamérica
}

\author{
PERSPECTIVES FOR PNEUMOCOCCAL CONJUGATE \\ VACCINES IN LATIN AMERICA
}

\author{
EDUARDO L. LÓPEZ
}

\section{INTRODUCCIÓN}

Streptococcus pneumoniae (neumococo) es una de las causas mas frecuentes de enfermedad grave en pacientes pediátricos. Así es considerado como el agente bacteriano que provoca el mayor numero de neumonías en niños, se estima que alrededor del $30 \%$ de las neumonías son causadas por este microorganismo ${ }^{1}$. Por otra parte es una de las causas principales de meningitis bacteriana aguda (MBA) en América Latina, estimándose que se producen alrededor de 9.000 casos por año en América Latina y el área del Caribe ${ }^{2}$.

En Argentina el neumococo es el segundo agente causal de MBA según datos oficiales como se observa en la Tabla 1. Como puede observarse en dicha tabla S. pneumoniae provocó 1.318 casos de esta patología en el período de 1997 al 2000, representando $25,3 \%$ del total de casos de las MBA con aislamiento etiológico. La mortalidad de las meningi- tis provocadas por este agente es entre 20 y $25 \%$ según los centros y un tercio de los niños quedan con secuelas severas ${ }^{3}$. Debe además recordarse que en Argentina hay un subregistro de alrededor del $30 \%$. Por lo tanto se podría considerar que fallece 1,7 niños por semana por esta patología. Si aceptamos esta cifra de mortalidad como un promedio para América Latina y asumiendo los datos publicados por H. Peltola, se podría decir que fallecen semanalmente 47 niños a causa de meningitis neumocóccica.

Además $S$. pneumoniae es el agente causal de la mayoría de los cuadros de bacteremia oculta en pacientes pediátricos. Estudios efectuados en Chile por R. Lagos et al han demostrado que en niños febriles, a quienes se les efectuaba hemocultivos de rutina, en un número significativo de los mismos se aislaba neumococo ${ }^{4}$.

También S. pneumoniae provoca un número considerable de neumonías en la niñez. Estudios efectuados en Europa y en E.U.A.. (Dallas) han de-

${ }^{1}$ Hospital de Niños Dr. Ricardo Gutiérrez y Facultad de Medicina, Universidad del Salvador. Buenos Aires, Argentina. 